\title{
FROM RELATIONAL TO TECHNOLOGICAL TRUST: HOW DO THE INTERNET OF THINGS AND BLOCKCHAIN TECHNOLOGY FIT IN?
}

\author{
Jorge De La Peña ${ }^{1}$, Eleni Papadonikolaki ${ }^{2}$ \\ ${ }^{1}$ Accenture, Madrid, Spain \\ ${ }^{2}$ University College London (UCL), London, United Kingdom
}

\begin{abstract}
The construction industry is complex, fragmented and struggles to cope with an intricate and geographically diverse Supply Chain (SC) where sophisticated flows of materials, information and capital take place in a dynamic environment. In this context, building trust among partners is a necessary requirement to deliver a successful project on time and on budget. This paper investigates the main factors that build inter-firm trust in large construction projects and explores the disruptive effect that the Internet of Things (IoT) and Blockchain (BC) could have in this process. The findings are based on an in-depth analysis of the literature and ten one-to-one telephone and face-toface interviews. The findings contribute to the literature by suggesting that a Blockchain-enabled IoT ecosystem has the potential to generate inter-firm trust at the front-end, during contract development, and throughout the construction phase. Moreover, the data denotes the need for further technological adoption in the construction industry as a means of smoothing the transition from relational trust to technological trust.
\end{abstract}

\section{Introduction}

The Supply Chain (SC) of a large construction project comprises a vast array of players - the client, consultants, designers, main contractor and subcontractors (Donyavi \& Flanagan, 2009). An intricate upstream and downstream flow of materials, information and capital takes place in a dynamic environment. Materials themselves account for $70 \%$ of the total cost of civil engineering projects (SiteSense, 2018). This denotes their contribution to project success and hence, the importance to efficiently manage them. Such a complex architecture demands real time control over every operation as well as a transparent network of players that trust each other. In addition, considering the complexity (Papadonikolaki, et al., 2017), fragmentation, and disputes (Zhang, et al., 2016) that characterise the construction industry, trust becomes a crucial ingredient for project success, which should be enabled through a transparent flow of information amongst stakeholders (Brady, 2014).

In practice however, opportunistic behaviour, mistrust and a lack of collaboration and information sharing in projects may arise. This is particularly relevant to temporary organisations that have a limited time to build trust with a temporary partner. The current theories of inter-firm trust are extensive, yet they tend to take a relational approach to explain the formation and maintenance of trust without considering the impact of disruptive technologies. This approach places trust on a person or organization once they are considered to have the adequate profile-fit to deliver a promise or contract (Day, et al., 2013). The problem arises when a profile-fit is mis-judged due to the relationship between two parties (relational trust) and this implicates a risk for the project.

Departing from this view, this paper investigates how the trust building process may change in construction ecosystems from trusting a person or organization based on their profile-fit (relational trust), towards trusting their technology. The evolution of device connectivity through the Internet of Things (IoT) as well as the emergence of distributed ledger technologies like Blockchain (BC), may provide a bridge to this transition. This paper formulates and responds to the following research question:

"To what extent can the IoT and BC technology generate inter-firm trust in large-scale construction projects?"

\section{Background}

\section{What is trust?}

Trust is a multidisciplinary area of study that has received a lot of attention in psychology, sociology, philosophy and business. From the most prominent definitions of trust, such as "a willingness to be vulnerable" (Mayer, et al., 1995), a "willingness to rely" (McAllister, 1995) or "confident, positive expectations" (Lewicki \& McAllister, 1998), we can note the work of (Rousseau, et al., 1998) who defined trust as "a psychological state comprising the intention to accept vulnerability based upon positive expectations of the intentions or behavior of another". Essentially, trust is based on a feeling of vulnerability, which is assumed by the trustor, based on the expectation or confidence on the trustee's actions. Trust has also been observed from multiple levels: interpersonal, inter-firm and intra-firm (Liu, 2015). In 
the construction industry, inter-firm trust cannot exist without a level of interpersonal trust amongst the main players (Lau \& Rowlinson, 2009). Interpersonal trust refers to the extent that an individual will trust another, based on the perception that they will not act opportunistically. On the other hand, inter-firm trust describes a situation where the members of an organization hold a collective perception of trust towards another entity (Gulati \& Nickerson, 2008). Consequently, the members of the contracting party must build trust at an interpersonal level with their client before inter-organizational trust can be realized.

\section{How does inter-firm trust emerge?}

Scholar have analyzed trust in the context of different cultures (Zaheer \& Zaheer, 2006), as a dynamic process (Lewicki, et al., 2006), as a process of continuous learning or as a network of relationships (Inkpen \& Curral, 2004). In the context of construction projects, inter-firm trust co-exists with interpersonal trust (Lau \& Rowlinson, 2009) and can be stimulated through a working history (Laan, et al., 2012). A much-needed synthesis of the literature was proposed by (Liu, 2015), who summarized the most notorious research on inter-firm trust in three categories: competence, reliability and goodwill. Table 1 below illustrates these, as well as the findings of Laan (2012).

Table 1: Main factors that build inter-firm trust

\begin{tabular}{|c|c|}
\hline Historical trust & Working history \\
\hline Competence & $\begin{array}{c}\text { Skills \& abilities } \\
\text { Reputation \& brand } \\
\text { Technical capabilities }\end{array}$ \\
\hline Reliability & Contract \\
\hline Goodwill & Mutual interest \\
\hline
\end{tabular}

In the context of the construction industry, a contractor must depict a high level of competence, reliability and goodwill for their client to trust them. Their competences are built through cognitive factors like skills, reputation, or technical capabilities. In comparison, their reliability is partially based on cognitive and institutional factors like contractual safeguards and mutual interests. Finally, the goodwill of a party is based on affective factors such as benevolence or integrity. The work of Liu (2015) emphasizes the importance of building strong tangible competences at the front-end, reliable contracts during the planning phase and developing inter-firm goodwill throughout the construction phase, in order to maintain a healthy communication and avoid any information asymmetries along the SC.

\section{The IoT: an end-to-end SC traceability ecosystem}

The IoT is a cyber-physical system that represents the evolution of device connectivity and denotes the convergence of the physical and the digital World. This is energized by the evolution of sensing technologies, Wireless Sensor Networks (WSN), middleware and cloud computing (Ben-Daya, et al., 2017). Scholars describe it as the "extension of the Internet and the Web into the physical realm" (Miorandi, et al., 2012) or "a decentralized system to allow cooperation amongst physical digital objects augmented with sensing/actuating, processing, storing, and networking capabilities" (Fortino \& Trunfio, 2014). Essentially, the IoT is "a network of physical objects that are digitally connected to sense, monitor and interact within and between a company and its SC" (Ben-Daya, et al., 2017).

In the context of a complex and dynamic environment such as the construction industry, the IoT provides a new generation of IT capabilities. Physical "things" communicate their properties in an automated manner, "providing new levels of SC visibility, agility and adaptability" (Childe, 2018). This provides a method of managing the complex flow of materials, information and capital that is ingrained in construction SC's (O'Brien, 2008). For instance, considering the correlation between the cost of materials and a project's total expenses, their quality and condition should always be monitored. To do so, IoT sensors can be deployed in batches of materials (e.g. rock, wood, or metal) to track their real-time geolocation, temperature, humidity, $\mathrm{pH}$ or stress, providing an end-to-end monitoring of the SC (Heiskanen, 2017). Such an IoT system could deliver the following improvements which are summarized in Figure 1 below:

1. An automated data transmission system: collects and sends real-time data from Radio Frequency Identification (RFID) tags to the chosen database.

2. Big Data analytics: the data gathered is cleaned, analyzed, and organized to enable interpretation.

3. An automated quality management system: the IoT-enabled RFID sensors act as "quality guarantors" as well as predicting a material's life cycle when combined with Big Data Analytics.

4. A dispute resolution mechanism: if a damaged material arrives on-site, it can be tracked back to the point where it damaged (e.g. between tier 3 and tier 4 its humidity levels increased by $90 \%$ ) hence, it is possible to allocate responsibility and liability to a specific party (e.g. tier 3).

5. Prevents information asymmetries along the SC, 
providing faster responses and decision-making: all authorized stakeholders are looking at the same pieces of information.

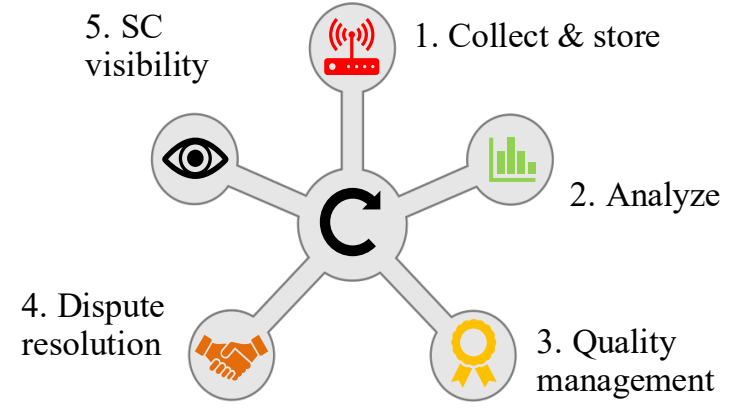

Figure 1: IoT ecosystem in construction projects

\section{How secure is an IoT ecosystem?}

Several scholars and Information Technology (IT) research organizations have addressed the importance of data privacy and security breaches in this arena. They argue that the IoT "lacks a central control", suffers from device heterogeneity and is vulnerable to cyber-attacks (Dorri, et al., 2016). This is particularly relevant for construction projects that demand a high level of connectivity for numerous heterogeneous IoT devices (Khajenasiria, et al., 2017). A survey conducted by the Global Digital Infrastructure Alliance identified four underlying security problems for the IoT: vulnerable network, weak application, limited authentication capabilities and unsafe endpoints (BCOT, 2017). Therefore, scholars and industry experts are increasingly looking at $\mathrm{BC}$ as the way to solve these vulnerabilities by securing an IoT ecosystem under a trusted, immutable, distributed ledger which results in an "Internet of Trusted Things" (Groopman \& Owyang, 2018).

\section{Blockchain (BC): securing an IoT ecosystem on a distributed ledger}

Distributed ledger technologies (DLT) are revolutionizing the process of storing data and the way people, firms and governments transact (Ray, 2018). Their distributed architecture, replication method and consensus mechanisms, eliminates the need to have a central authority that governs and maintains the ledger (Mills, et al., 2016). BC is an example of a technology that has harnessed the potential of DLT's while innovating upon them. On the one hand, it is distributed by nature and managed across a peer-topeer network of participants that do not need to rely on a central authority. On the other hand, it has a unique structure whereby the data is stored in "blocks" that are secured and chained to each other using cryptography. Each block contains specific data regarding a transaction (monetary or non-monetary) which is used to generate a cryptographic key known as the "hash". This is used to chain the blocks together, and whenever a new block is added to the chain, it must contain the hash of its predecessor. This makes it essentially impossible to alter the data inside the blocks, making this technology immutable, tamperproof and secure (Swan, 2015).

A BC can be built as a public distributed ledger or alternatively, as a private one. In both cases, the ledger has a distributed architecture that is tamper-proof, immutable and secure. Notwithstanding, they differ in who can participate, who maintains the ledger and how to reach "consensus" (the procedure to add a new block to the chain). Public BC's use a completely decentralized management system whereby anyone has the authority to participate and become a node, either as a user (e.g. entering in a transaction) or as a "miner" (verifying transactions). In comparison, a private $\mathrm{BC}$ uses a semi-centralized structure to govern the distributed ledger, where participants need an invitation to take part in the $\mathrm{BC}$ and only those that are authorized can access the data inside the blocks, improving the privacy of participants (Chen, 2017). Public BC's are maintained by any node that decides to mine while private $\mathrm{BC}^{\prime} \mathrm{s}$ by those that become miners by invitation. In a public BC, "miners" must solve complicated mathematical puzzles through a "proof-of work" (PoW) or "proof of stake" (PoS) algorithm and once "consensus" is reached, the block can be added to the chain, containing the hash of its predecessor. In comparison, the "consensus" protocols in a private $\mathrm{BC}$ are not usually based on the PoW or PoS algorithm for three main reasons. Firstly, this extra layer of security is unnecessary when the profile of participant is not encrypted. Secondly, the PoW reduces throughput (transactions per second) in private Blockchains. Finally, the energy cost for mining transactions is too high at low scales. In this case, a trusted team is typically allocated to manage the consensus process, which in a construction project it might be the main project manager, the architect, the engineer or the client itself.

A private $\mathrm{BC}$ may complement an IoT-enabled $\mathrm{SC}$ in the following ways (Figure 2 below illustrates this):

1. A distributed architecture: improves data security.

2. Immutability: the IoT data in BC is tamper-proof.

3. Transparency: all the data is transparent to authorized participants, reducing the room for opportunistic behavior.

4. Dispute resolution mechanism: reinforcing the traceability capabilities of the IoT and using Smart Contracts

5. Stakeholder involvement: the client is able to track the development of materials through the $\mathrm{BC}$ hence, it acts as a real-time traceability platform. 
Together, these technologies deliver the following benefits: (a) Faster responses \& decision-making, (b) Automated data transmission system, (c) Automated Quality Management, (d) SC traceability, (e) Security, (f) Dispute resolution mechanism, (g) Transparency, and (h) Stakeholder involvement.

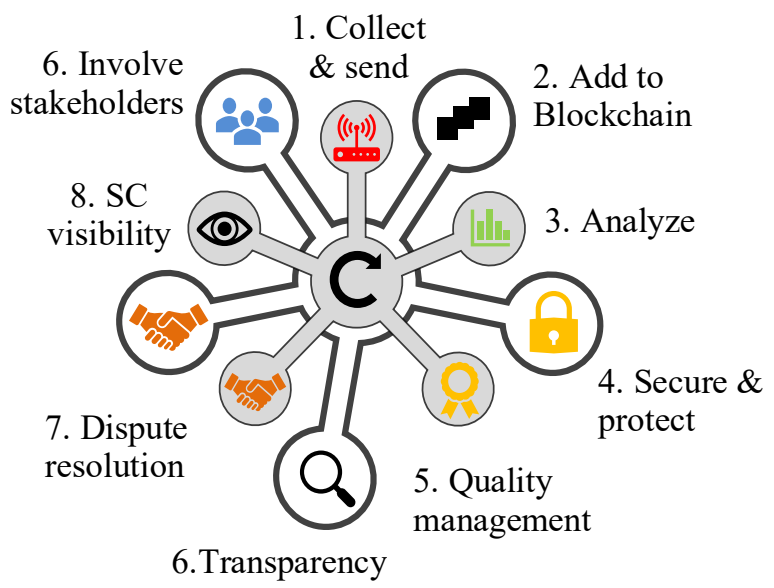

Figure 2: How a BC complements an IoT ecosystem

The IoT may serve to improve transparency through $\mathrm{SC}$ visibility and monitoring, while $\mathrm{BC}$ technology is able to secure this ecosystem and provide a real time traceability platform. This allows to involve all stakeholders while providing an accurate quality management system and a dispute resolution mechanism. Such a system avoids the implicit risk of trusting a person or organization from a relational standpoint, where the actual level of competences, reliability or goodwill of a party might be obscured. Instead, trusting a technology might be more secure and less ambiguous than trusting people, hence helping to eliminate the "feeling of vulnerability" that Rousseau (1998) considers imperative in the trust building process of an individual.

\section{Research gap}

The process of building inter-firm trust in a construction scenario is complex, dynamic, and overlaps with the process of building interpersonal trust. Inter-firm trust theories have provided substantial evidence of the factors that stimulate trust in the construction industry. Notwithstanding, this paper aims to fill a gap in the research of Liu (2015), given the lack of consideration given to potential that disruptive technologies have in the process of building inter-firm trust. The IoT and BC fit the description of "disruptive technology" as proposed by Christensen (1995), since they have initially underperformed compared to mainstream solutions like ERP systems, given their lack of scalability, high cost and clients resistance to change. Notwithstanding, the same multinationals that offer these ERP systems (e.g.
ORACLE or SAP), have integrated some of their capabilities, to enhance their current ERP offerings, a transition known as "competence enhancing disruptive technologies" (Daneels, 2004). Eventually however, disruptive technologies can destroy the competences of those unable to commit enough resources to fuel their transition, leading to a process of creativedestruction (Schumpeter, 1942). This process energizes the transition from one sociotechnical constellation where relationships where are the heart of building trust in the construction industry, towards a refined sociotechnical constellation where disruptive technologies play a role that must be acknowledged.

\section{Methodology}

This paper investigates the process of building trust with a client from a contractor's viewpoint and how disruptive technologies can contribute to this process. Specifically, we aim to answer the following research question:

"To what extent can the IoT and BC technology generate inter-firm trust in large-scale construction projects?"

To do so, a combination of secondary and primary research has been adopted. The secondary research provides the foundation for analysis by examining previous research on inter-firm trust, IoT and BC. This serves as a lens to direct the primary research which is based on ten one-to-one, non-standardized and semistructured telephone and face-to-face in-depth interviews. Open-ended questions allowed the interviewees to lead the discussion, delivering valuable and unexpected findings. In addition, the interviews opened with some questions regarding the size of the firm in question, and a description of a large construction project that the interviewees had dealt with. This improves the reliability and validity of responses and allows to contextualize the findings for large construction projects. Specifically, the choice has been to interview a wide spectrum of professionals working for contractors or clients involved in large construction projects, as well as experts in IoT and BC. The interviewees (IDs) that were selected from the contracting side includes a project manager, a project director, an operation director, and a Chief Financial Officer (CFO). Their expertise lies on a different phase of the projects (bidding, design, or construction) to cover the entire project lifecycle. In the client side, we interviewed a client, a consultant, an architect and an engineer who is also a Chief Executive Officer (CEO). These oversee the selection of the main contractor and the design of the project itself. In terms of technology experts, we have interviewed members of BC consortiums, researchers, a Chief Technology Officer (CTO), and the leader of the biggest IoT ecosystem in France (Objenious). Table 2 below displays the profile and experience of the interviewees and identifies them using the term (ID). It is arranged by colors to divide them in three categories; technology (light shade), 
client (medium shade) and contractor (dark shade) respectively. Interviewee (4) plays a double role in the interview since it is a technology expert and a member of the client team. Similarly, interviewee (7) is a project director as well as an investor (client).

Table 2: Interviewee's identification (ID) and profiles

\begin{tabular}{|c|c|c|}
\hline ID & Profile & Experience \\
\hline 1 & $\begin{array}{l}\text { Head of partnerships and } \\
\text { indirect channels at Objenious }\end{array}$ & $\begin{array}{l}\text { IoT } \\
\text { Ecosystem in } \\
\text { France }\end{array}$ \\
\hline 2 & $\begin{array}{l}\text { General director of notaries; } \\
\text { Economics \& technology } \\
\text { expert; Blockchain researcher }\end{array}$ & $\begin{array}{l}\text { BC security } \\
\text { researcher }\end{array}$ \\
\hline 3 & $\begin{array}{l}\text { CTO at Beikei; } \\
\text { Co-founder at NotaBlock; } \\
\text { Stanford Postgraduate }\end{array}$ & $\begin{array}{l}\text { BC start-up } \\
\text { in the legal } \\
\text { spectrum }\end{array}$ \\
\hline 4 & $\begin{array}{l}\text { Senior Project Manager at } \\
\text { Mace bidding phase; } \\
\text { Construction Blockchain } \\
\text { Consortium (CBC) member }\end{array}$ & $\begin{array}{l}10+\text { years of } \\
\text { experience in } \\
\text { construction } \\
\text { bidding }\end{array}$ \\
\hline 5 & $\begin{array}{l}\text { CEO and technical director of } \\
\text { TBI focused on engineering } \\
\text { design and construction }\end{array}$ & $\begin{array}{l}30+\text { years of } \\
\text { experience in } \\
\text { engineering }\end{array}$ \\
\hline 6 & $\begin{array}{l}\text { Architect and project director } \\
\text { at Metalocus }\end{array}$ & $\begin{array}{l}20+\text { years of } \\
\text { experience in } \\
\text { architecture }\end{array}$ \\
\hline 7 & $\begin{array}{l}\text { Project Director and investor } \\
\text { at Cobra Group focused on the } \\
\text { construction phase }\end{array}$ & $\begin{array}{l}15+\text { years of } \\
\text { experience in } \\
\text { EPC projects }\end{array}$ \\
\hline 8 & $\begin{array}{l}\text { Commercial Operations } \\
\text { Director at Cobra Group }\end{array}$ & $\begin{array}{l}35+\text { years of } \\
\text { experience in } \\
\text { EPC projects }\end{array}$ \\
\hline 9 & $\begin{array}{l}\text { Project Manager focused on } \\
\text { the tendering phase at Vinci }\end{array}$ & $\begin{array}{l}4+\text { years of } \\
\text { experience in } \\
\text { tendering }\end{array}$ \\
\hline 10 & $\begin{array}{l}\mathrm{CFO} \text { of } \\
\text { Construction }\end{array}$ & $\begin{array}{l}35+\text { years in } \\
\text { project } \\
\text { finance }\end{array}$ \\
\hline
\end{tabular}

\section{Data collection and findings}

According to Lau and Rowlinson (2009), the competences of a contractor - skills \& abilities, reputation \& brand, and professional capabilities are important contributors to inter-firm trust at an early stage in a project. These cognitive factors are important when selecting a partner at the front-end. Having experience in large construction projects was found to be crucial. According to interviewee (10) "trust is most probably coming from the historical record of the company, and the fact that we have got significant similar projects already built". Moreover, from the contracting side, interviewee (7) and (8) consider that having good references is key to build trust during the bidding phase since they portray the competences that a company holds. From the client side, interviewees (4) and (5) agree that references are important, and as interviewee (5) described - "I always say you need references, because that means that other companies made this selection before". Moreover, interviewees (5), (6), (7), (8), (9) agree that innovation is another winning factor during bidding, especially if the project is technological - "innovation is critical" (ID-7). Having a working history with a client was found to improve the chances to be invited to bid. However, as interviewee (6) explained: "If you had a previous experience, you are more likely to be invited but once invited, other factors like technical capacity or innovation play a bigger role in their decision". Interestingly, interviewee (4) added that: "I tend to challenge every contractor that I've worked with more, to be more collaborative that they were before" and that "I may be harder on them".

An important part of the reliability of a contractor is assessed during the contract development, in terms of its "consistency, the clarification of responsibility, duration and mutual interests of contract" (Liu, 2015). Given the fact that contracts for large construction projects are characterized by being based on incomplete information (Walker \& Pryke, 2011), interviewee (5) argues that "with the private client, contracts need to be more flexible and adaptable to all changes, so in some way this demands to have a continuous contact with the client". All interviewees (100\%) agree that conflicts tend to be expensive, and some argue that negotiation or mediation (ID-4, 7, 8) are good strategies to avoid expensive litigation. Contracts must hence include a dispute resolution mechanism to handle litigation or conflict, add reliability, and increase the client's trustworthiness.

The reliability that a contractor builds through the contract development evolves during the construction phase in multiple ways. Firstly, through the degree that general contractual requirements have been met (100\% of the interviewees considered this crucial). According to interviewee (9): "the client needs to be sure that all the requirements that we have signed in our contract are being delivered in accordance with the contract". Secondly, by maintaining the quality standards that were stipulated in the contract, where all the contractors interviewed $(100 \%)$ view it as a necessary thing to build reliability and earn the trust of the client. Thirdly, through goodwill, being the positive intentions and relationship with another party. This is an essential element for inter-firm trust to evolve beyond the bidding and contractual phases and 
is highly influenced by:

(a) The degree of information shared.

Contractors consider that communicating and sharing information with their clients is at the heart of building trust beyond contract development. Interviewee (6) holds that "during the construction phase, the key to generate trust is the information" and interviewee (10) believes that "trust in construction comes from human communication and assurance of good information with regards to the progress". During the construction phase, they regard information as a fundamental factor to generate trust. Similarly, clients view this information as an asset to improve decision-making. Notwithstanding, as interviewee (7) clarified: "I don't need just data, I need conclusions based on this information, and this is the key point".

(b) The collaboration demonstrated.

To improve trust and maintain a smooth flow of information with the client, interviewee (8) and (9) stressed the importance of integrating their SC. For interviewee (9), "a project necessarily needs to be built on trust between the partners, otherwise it cannot go any further." They claim that clients value a private firm that is doing well with their partners, since having many stakeholders that do not work collaboratively can lead to mistrust.

(c) The involvement of the parties.

The client's design and engineering team considers important to implicate the client with the main stakeholders involved in the project. As interviewee (5) explained: "we always present to the client the main people in charge of the different areas in the project to build this trust". This way, they can generate interpersonal trust to enable inter-firm trust to flourish as proposed by Lau \& Rowlinson (2009). In addition, involving the client by maintaining them updated with the development of the project is crucial. Today, this tends to be done through a combination of progress reports (weekly, monthly or quarterly), meetings, online platforms or BIM.

\section{How can the IoT and BC generate inter-firm trust?}

In terms of its applications, the sensors can be used to track the geolocation, temperature or humidity of materials. Interviewee (1) claims they can optimize the route of trucks to "avoid making traffic jams", perform "predictive maintenance of tools", "monitor the worksite", "monitor the employees themselves", "provide safety on-site", or "saving energy during the building process". Additionally, the information is secured and encrypted, and the client can access it in real time using an online platform. Furthermore, "the data is made very understandable" (through analytics), so the client can track the geolocation and properties of everything without a technical background. Interviewee (1) emphasized that "trust is the good aspect of IoT because the data through IoT couldn't lie".

During the bidding phase, interviewee (1) claims that "the IoT is the answer to differentiation through innovation" and, "it could help to win the projects". In terms of its application as a dispute resolution mechanism, "as data does not lie, it will certainly help to eradicate any conflict on the project". Moreover, the IoT was found to act as a quality management tool, while saving time and increasing productivity on the job-site. As interviewee (1) explained - "we built the platform for that". The integration of a fully functional IoT ecosystem can take between 9-15 months if the client's familiarity with the technology is high, otherwise it can extend more than 15 months and its price can be "as low as 50000 euros to more than 1 million euros". Interviewee (4) reinforced these views adding that: "you can prevent the amount of time wasted just looking for things and it increases productivity on the job-site".

According to interviewee (4) " $B C$ itself is an immutable distributed ledger that tracks all of the different steps and verifies and approves the processes". In addition, "it can help to solve conflicts because it can "improve auditability, therefore providing much more information to do dispute resolution". In the context of a construction SC, interviewee (3) claims that "blockchain provides us with an opportunity to monitor the history of all these components and to have easier access to this information". He also assures that - "this way it's easier to hold someone accountable for the failure of a project or a specific component". In addition, interviewee (2) holds that "Blockchain is a very useful technology because it's able to give us security about the data that has been recorded in any kind of technological application". In terms of cost effectiveness, interviewee (3) argues that private BC's are cheaper to run and 'it's easier to maintain, that's why most enterprises use it as the solution instead of using a public Blockchain". Moreover interviewee (2) argues that with the "proof of work" algorithm, energy costs are high because a lot of computation power is needed. Notwithstanding he argues that "you achieve the same result if you use a proof of stake" and "you only need a very simple personal computer and with that is enough for each miner". In addition, interviewee (4) added that "you can use a private BC" and emphasized the importance of using that information after, in order to learn from it - "You 
know, how owners can use this information for its further maintenance and operation schedule?".

\section{Discussion and analysis}

\section{At the front-end: trust evaluation}

Several studies have claimed that having a working history with a client has an influence on inter-firm trust and increases the chances of being selected for a project - these claims were confirmed by Laan, et al. (2012). Our findings suggest a similar pattern, as the members of the contracting party that were interviewed (ID-8, 9, 10) agreed that having worked with a client in the past is helpful to get invited to a bidding process however, once invited, other factors like competences, price and innovation play a role. Interestingly, the existence of a working history may create a challenge for the contractor when the client's team decides to further improve their work standards through intensive investigations (ID-4).

The process of building trust with a client starts at the front-end, where the accumulated professional experience, references and reputation of contractors is crucial to win a bid for a large construction project. These are defined as competences by Liu (2015) and they englobe a wide spectrum of features such as skills, abilities, experiences, qualifications, reputation or brand value. These constitute the cognitive factors affecting the perceived trustworthiness of the contractor in the eyes of the client and are portrayed through their professional skills and references. Having strong competences conveys a feeling of security and confidence that leads to a positive evaluation of the trustworthiness of a contractor at the front-end (Laan, et al., 2012). Consequently, this increases their likelihood of being awarded a project.

In the current digital age, the findings suggest that it is increasingly important for contractors to acquire innovative technologies that secure and guarantee a high level of competences. In this context, the IoT was found to provide this level of innovativeness deriving in a method of differentiation in the bidding stage (ID1). This technology provides the client with a new level of SC visibility while supporting the integration of a contractor's SC which improves a client's reliability. In addition, $\mathrm{BC}$ professionals (ID-2, 3) consider that a private $\mathrm{BC}$ can be used to improve the security and transparency of an IoT ecosystem.

At the front-end of a project we can conclude that the main factors affecting the level of trust with a client are the competences of a contractor. According to Liu (2015), these are their professional experience, skills, abilities and reputation, with no consideration of disruptive technologies. This paper fills this gap and suggests that technological capabilities arising from disruptive technologies such as the IoT and $\mathrm{BC}$ also enhance the competences of a contractor. In turn, they become a helpful criterion during the bidding phase.

\section{Contract development phase: trust development}

During the contract development, certain cognitive and affective factors come into play, and the development of trust begins, based on the perceived reliability of the contractor. A contract assigns risks and responsibilities to the parties involved, however, these are based on incomplete information and are subject to change throughout the project (Walker \& Pryke, 2011). Flexible and open contracts were found to be essential, given the uncertain nature of the industry and the inherent complexity of large construction projects (Papadonikolaki, et al., 2017). Moreover, given that disputes are common in the construction industry (Zhang, et al., 2016), and since contracts may not cover future hidden risks, having a powerful dispute resolution mechanism between both parties is a crucial asset. The findings suggest that it adds reliability to a contractor, and trust to a client. This is especially important to avoid entering into expensive litigation, where the findings suggest that both the contractor and the client team prefer to solve them through negotiation or mediation (ID-4, 7, 8).

This paper agrees with the work of Childe (2018) and Ben-Daya et al. (2017) on how the IoT improves SC visibility, agility and adaptability. In addition, it proposes that the capabilities of the IoT can also serve as a new way of resolving conflicts related to material quality management, on-site worker performance or variable cost handling (ID-1). The data can be gathered wherever a sensor is integrated (e.g. materials, trucks, people or tools). It can be argued that this data is vulnerable to cyber-attacks and is not tamper-proof (BCOT, 2017). Notwithstanding, findings suggest that $\mathrm{BC}$ may serve as a method of avoiding this whilst improving auditability, therefore "providing much more information in order to do dispute resolution" (ID-4). As such, being able to track these variables along the SC, applying data analytics and finally safely storing them in a private $\mathrm{BC}$, allows both parties to precisely allocate responsibility for: (i) any damaged materials or unexpected circumstance (e.g. lost materials), (ii) a lack of on-site performance (e.g. workers effort analysis), or (iii) a sudden increase in costs (e.g. energy bills).

\section{During the construction phase: trust evolution}

During the construction phase, the trust that has been developed at the front-end and during contract development evolves in different directions depending on the performance of the contractor (Liu, 2015). This paper suggests that performance is measured by the degree that contractual requirements are being met, the 
level of quality standards being offered, and the level of goodwill demonstrated. The competences of a contractor deliver a specific standard of quality and a degree of compliance with contractual requirements, both being considered by all interviewees as crucial elements for inter-firm trust to evolve. To keep up with contractual requirements, the contractors maintained their clients informed of the development of the project while keeping up with Key Performance Indicators (KPI). In this sense, the capabilities of the IoT and $\mathrm{BC}$, in terms of traceability, monitoring of quality properties, and security of data, were found to act as quality guarantors. This allows to monitor what contractual requirements have been met, and what level of quality standards has been delivered. In terms of goodwill, this is determined by the level of information shared, collaboration demonstrated and involvement of the parties.

Sharing information is becoming increasingly important for contractors since efficient communication system are increasingly valued by clients (Papadonikolaki \& Wamelink, 2017). All the contractors interviewed used a combination of weekly, monthly or quarterly reports, BIM or online platforms to keep their clients informed of the development of the project. From the client's point of view, the information being delivered must be understandable and useful for decision-making, not just raw data (ID7). As such, the data gathered from the IoT sensors is cleaned, organized, secured through a private $\mathrm{BC}$ and presented to the client through a user-friendly interface where no technical knowledge is needed. This enables a client to efficiently monitor a project online, providing a new source of sharing information and an efficient method of portraying a contractor's competences, reliability and goodwill, all under one trusted platform. In addition, this also provides the opportunity to anticipate any changes in transportation times, delays or quality variations that have important implications for the project time and cost, which ultimately affects the client's perceived trustworthiness of the contractor.

In terms of collaboration and involvement, it was found that integrating a SC is an important contributor to inter-firm trust. By maintaining a smooth flow of information and a healthy collaboration between partners, contractors can avoid information asymmetries while improving performance, which ultimately leads to a perception of reliability for the client. To do so, the contractors either shared a database with their partners, e.g. access to a web-based platform, where the client had limited access, or more traditional electronic document management systems, e.g. google drive, or more sophisticated software's like BIM. This allowed the partners to share information, collaborate, and then involve the client through progress reports. Notwithstanding, the client was not offered the possibility of tracking the development of the project in real time and they had to wait for these progress reports to be written. The IoT allows to improve collaboration between partners by allowing sensors to communicate to different tiers in the SC simultaneously, as well as keeping all the information under the same database (BC). This means that every partner is looking at the same information and better decision-making can be enacted. From the client's side, an online platform where they can track anything related to their project in real time and without technical knowledge is a method of involving them and was found to contribute to the evolvement of trust.

\section{Conclusions and suggestions}

This paper has investigated the main factors that contribute to the evaluation, development and evolution of inter-firm trust at the front-end, during contract development, and throughout the construction phase of large construction projects. It offers an empirical investigation of the extent to which these factors can be achieved using the IoT and $\mathrm{BC}$, tackling its main research question and contributing to the work of Liu (2015) in the following ways:

1. At the front-end, the competences of a contractor are built through their professional experience (skills and project experience), their technological capabilities (fostered by disruptive technologies), and their reputation (portrayed through references), all having an influence on the likelihood of being awarded a project. Having a working history improves the chances of being invited to bid without giving a guarantee of being selected.

2. During contract development, the main factors affecting trust lie in the degree of openness and flexibility of the contract, and the degree to which it includes a robust dispute resolution mechanism that avoids expensive litigation.

3. During the construction phase, the main factors affecting inter-firm trust are the degree that contractual requirements are being met, the level of quality standards being offered, and the level of goodwill demonstrated (in terms of information shared, collaboration demonstrated and involvement of the parties).

These findings were complemented with the unveiled potential that can be derived from the IoT and BC and how it may contribute to the development of inter-firm trust, hence answering the main research question of this study. While the IoT can sense an environment and collect data from it in an automated manner, a private $\mathrm{BC}$ can secure this ecosystem using a 
distributed architecture secured through cryptography. Together, a Blockchain-enabled IoT ecosystem offers an automated data transmission system that allows efficient quality management, dispute resolution, SC traceability, transparency, security, reduction of information asymmetries, stakeholder involvement, faster responses and efficient decision-making. These attributes were found to promote a client's reliance and trust towards a contractor. Moreover, the technology provides a method of monitoring the development of large construction projects from end-to-end. This derives in the next generation of SC visibility, auditability, transparency, and a method of sharing information, collaborating with partners and involving the client.

During the lifecycle of a project, the IoT and BC was found to have the potential to contribute to inter-firm trust in the following ways:

1. At the front end, they stimulate the formation of trust by enhancing the competences of a contractor from different angles. Firstly, by enhancing their skills and capabilities. Secondly, by enhancing their technological capabilities and finally, by improving their reputation.

2. During contract development, they provide a new method for dispute resolution by keeping a detailed, digital and immutable record of a project so both parties avoid expensive litigation. This was found to improve the reliability of a client while stimulating the development of trust.

3. During the construction phase, this ecosystem delivers value though a digital platform that enables information to be shared in a transparent, secure and immutable manner. In turn, the client benefits from an integrated SC where contractual requirements and quality standards can be accurately monitored. This enhances the perceived goodwill of a contractor.

As a final remark, we cannot neglect that these are still novel technologies that need some time to flourish so that their full potential can be embraced at an industry level. Nevertheless, in this dynamic environment, it is imperative for construction firms to embrace this transition by updating their technological capabilities and while fostering their supply chain relations.

\section{References}

BCOT, B. o. T. (2017) Blockchain of Things, BCOT (White Paper). s.1.:BCOT.

Ben-Daya, M., Hassini, E. \& Bahroun, Z. (2017) Internet of things and supply chain management: a literature review. International Journal of Production Research, pp. 1-24.
Brady, D. (2014) Using visual management to improve transparency in planning and control in construction. University of Salford.

Chen, E. (2017) An approach for improving transparency and traceability of industrial supply chain with Blockchain technology. Finland: Tampere University of Technology.

Childe, S. (2018) Supply chain agility, adaptability and alignment: empirical evidence from the Indian auto components industry. International Journal of Operations and Production Management, 38(1), pp. 129-148.

Christensen, C. \& Bower, J. (1995) Disruptive Technologies: Catching the Wave. Harvard Business Review, pp. 43-53.

Daneels, E. (2004) Disruptive Technology Reconsidered: A Critique and Research Agenda. The Journal of Product Innovation Management, pp. 246-258.

Day, M., Fawcett, S., Fawcett, A. \& Magnan, G. (2013) Trust and relational embeddedness: Exploring a paradox of trust pattern development in key supplier relationships. Industrial Marketing Management, 42(2), pp. 152-165.

Donyavi, S. \& Flanagan, R. (2009) The impact of effective material management on construction site performance for small and medium sized construction enterprises. In: Proceedings of the 25thAnnual ARCOM Conference. Nottingham, UK, pp. 11-20.

Dorri, A., Kanhere, S. \& Jurdak, R. (2016) Blockchain in internet of things: Challenges and Solutions. Corr.

Fortino, G. \& Trunfio, P. (2014) Preface of Internet of Things based on Smart Objects: Technology, Middleware and Applications. 1st ed. Switzerland: Springer.

Groopman, G. \& Owyang, J. (2018) The Internet of Trusted Things Blockchain as the Foundation for Autonomous Products \& Ecosystem Services, s.1.: Kaleido Insights.

Gulati, R. \& Nickerson, J. (2008) Interorganizational trust, governance choice, and exchange performance. Organization Science, 19(5), p. $688-708$.

Heiskanen, A. (2017) The technology of trust: How the Internet of Things and blockchain could usher in a new era of construction 
productivity. Construction Research and Innovation, 8(2), pp. 66-70.

Inkpen, A. \& Curral, S. (2004) The coevolution of trust, control, and learning in joint ventures. Orgnization Science, 15(5), pp. 586-599.

Kale, S. \& Barnes, J. (1992) Understanding the Domain of Cross-National Buyer-Seller Interactions. Journal of International Business Studies, 23(1), p. 101-132.

Khajenasiria, I., Estebsarib, A., Verhelsta, M. \& Gielena, G. (2017) A review on Internet of Things solutions for intelligent energy control in buildings for smart city applications. Energy Procedia, p. 770 - 779 .

Laan, A., Voordijk, H., Noorderhaven, N. \& Dewulf, G. (2012) Levels of Interorganizational Trust in Construction Projects: Empirical Evidence. Journal of construction engineering and management, 138(7), pp. 821-831.

Lau, E. \& Rowlinson, S. (2009) Interpersonal trust and inter-firm trust in construction projects. Construction Management and Economics, 27(6), pp. 539-554.

Lewicki, R. \& McAllister, D. (1998) Trust and distrust: new relationships and realities. Academy of Management Review , 23(3), pp. 438-458. .

Lewicki, R., Tomlinson, E. \& Gillespie, N. (2006) Models of Interpersonal Trust Development: Theoretical Approaches, Empirical Evidence, and Future Directions. Journal of Management, 32(6), pp. 991-1022.

Liu, Z. (2015) Trust between Organizations: A Review of Current Research and Recommendation for the Future. Review of Contemporary Business Research, 4(1), pp. 40-48.

Mayer, R., Davis, J. \& Schoorman, D. (1995) An Integrative Model of Organizational Trust. The Academy of Management Review, 20(3), pp. 709-734.

McAllister, D. (1995) Affect- and Cognition-Based Trust Formations for Interpersonal Cooperation in Organizations. The Academy of Management Journal, 3(1), pp. 24-59.

Mills, D. et al. (2016) Distributed ledger technology in payments, clearing, and settlement. Journal of Financial Market Infrastructures, 6(2/3), pp. 207-249.
Miorandi, D., Sicari, S., Pellegrini, D. \& Chlamtac, I. (2012) Internet of Things: Vision, Applications and Research Challenges. Ad Hoc Networks, 10(7), p. 1497-1516.

O'Brien, W. F. C. R. V. L. K. (2008) Construction Supply Chain Management handbook. 1st ed. Florida: CRC press.

Papadonikolaki, E., Verbraeck, A. \& Vamelink, H. (2017) Formal and informal relations within BIM-enabled supply chain partnerships. Construction Management and Economics, pp. 1-22.

Papadonikolaki, E. \& Wamelink, H. (2017) Inter-and intra-organizational conditions for supply chain integration with BIM. Building Research \& Information, 45(6), pp. 649-664.

Ray, S. (2018) The Difference Between Blockchains \& Distributed Ledger Technology. [Online] Available at: https://towardsdatascience.com/thedifference-between-blockchains-distributedledger-technology-42715a0fa92 [Accessed 1512 2018].

Rousseau, D., Sitkin, S., Burt, R. \& Camerer, C. (1998) Not so different after all: A crossdiscipline view of trust. Acadomy of Management Review, 23(3), pp. 393-404.

Schumpeter, J. (1942) Creative destruction. Capitalism, socialism and democracy, pp. 82-85.

SiteSense. (2018) Mobile Site Material Tracking, s.l.: Intelliwave Technologies.

Swan, M. (2015) Blockchain, blueprint for a new economy. 1st ed. s.1.:O'Reilly.

Walker, F. \& Pryke, S. (2011) Investigating the Relationship between Construction Contract Documentation Incompleteness and Project Transaction Characteristics: The Frequency Characteristic. London, RICS Construction and Property Conference.

Zaheer, S. \& Zaheer, A. (2006) Trust across borders. Journal of International Business Studies, pp. 21-29.

Zhang, S., Fu, F., Gao, Y. \& Zheng, X. (2016) Influence of trust and contract on dispute negotiation behavioral strategy in construction subcontracting. Journal of Management in Engineering, 32(4). 